\title{
Reduction of Fruit Load Affects Early Fruit Growth in Apple by Enhancing Carbohydrate Availability, Altering the Expression of Cell Production-related Genes, and Increasing Cell Production
}

\author{
Madhumita Dash ${ }^{\mathbf{1}}$, Lisa Klima Johnson, and Anish Malladi ${ }^{2}$ \\ Department of Horticulture, University of Georgia, 1111 Miller Plant Sciences, Athens, GA 30602
}

\begin{abstract}
Additional Index words. cell division, cell expansion, fruit size, source-sink relationship, thinning
ABstract. Carbohydrate availability is a key factor determining fruit growth in apple (Malus $\times$ domestica) and other fruits. However, the molecular mechanisms regulating fleshy fruit growth in response to changes in carbohydrate availability are not well understood. In this study, carbohydrate availability was manipulated by reducing fruit load, and its effects on apple fruit growth, cell production and expansion, and the expression of genes associated with these processes was investigated. Reduction of fruit load during early fruit development led to a rapid increase in early fruit growth. The increase in fruit growth was associated with a transient increase in sorbitol and fructose concentrations and altered expression of sorbitol dehydrogenase and sucrose synthase genes. Increase in early fruit growth was mediated primarily by an increase in cell production. The aintegumenta gene, MdANT1, an AP2-domain transcription factor associated with the regulation of cell production and fruit growth, displayed an increase in expression by up to 5 -fold during early fruit development in response to the reduction in fruit load. Additionally, multiple cell cycle genes positively associated with cell production such as the cyclins, MdCYCA2;1, MdCYCA2;3, MdCYCB1;1, and MdCYCB2;2, and the B-type cyclin-dependent kinases, MdCDKB1;1, MdCDKB1;2, and MdCDKB2;2, displayed higher expression by up to 5 -fold under reduced fruit load conditions during early fruit growth. These data indicate that carbohydrate availability affects the expression of key transcription factors and cell proliferation genes, thereby regulating cell production during early fruit growth. Several genes associated with cell expansion such as the expansins, and cobra and cobra-like genes, also displayed altered expression in response to the reduction in fruit load. The expression of three expansin genes was higher under reduced fruit load conditions at maturity, a stage at which a minor increase in cell size was apparent. Together, data from this study indicate that fruit load reduction induces changes in carbohydrate availability and metabolism, which in turn affect cell production-related mechanisms, thereby enhancing early fruit growth.
\end{abstract}

Fruit growth in apple and other fruits is greatly dependent on and often limited by carbohydrate availability (Bertin et al., 2002; Lakso et al., 1998, 1999). In apple, fruit growth is sensitive to carbohydrate limitation during early $(\approx 2$ to 3 weeks after bloom) and at late stages of fruit development (Lakso et al., 1998, 1999). Early fruit development is particularly sensitive to carbohydrate limitation because it is often highly responsive to treatments that alter carbohydrate availability (Dash et al., 2012; Dash and Malladi, 2012; Goffinet et al., 1995; Link, 2000; Wismer et al., 1995). Similarly, in other fruits such as tomato (Solanum lycopersicum), fruit growth is limited by carbohydrate availability during early development (Baldet et al., 2002; Bertin, 2005; Bertin et al., 2002). Reduction of fruit load during early fruit development has been used to study the effects of changes in carbohydrate availability on fruit growth (Baldet et al., 2006; Bertin, 2005; Bertin et al., 2002; Goffinet et al., 1995; Morandi et al., 2008). Reduction of fruit load during early fruit development may

Received for publication 1 May 2013. Accepted for publication 4 June 2013. We thank the staff at the Georgia Mountain Research and Education Center in Blairsville, GA, for tree maintenance and help with the fruit load reduction experiment. We thank Dr. Phil Brannen for the trees used in this study. We thank Betty Schroeder and Dr. Stanley Kays for assistance with carbohydrate measurement using gas chromatography.

${ }^{1}$ Present address: School of Forest Resources and Environmental Sciences, Michigan Technological University, Houghton, MI 49931.

${ }^{2}$ Corresponding author. E-mail: malladi@uga.edu. increase carbohydrate availability to other sinks, including the remaining fruit, thereby allowing for fruit growth to progress under less limiting conditions. For example, reduction of fruit load lowered the hexose:sucrose ratio and enhanced fruit growth rate in peach [Prunus persica (Morandi et al., 2008)]. Similarly in tomato, reduction of fruit load during early development altered starch and sugar content, enhanced fruit growth, and increased final fruit size (Prudent et al., 2010). In Rosaceae plants including apple, sorbitol and sucrose are the main translocated carbohydrates, with sorbitol constituting the majority (Bieleski, 1969). A reduction of fruit load enhanced apple fruit growth (Dash and Malladi, 2012; Goffinet et al., 1995), potentially by decreasing competition for these translocated carbohydrates.

Sensitivity of the early stages of fruit development to carbohydrate availability may be attributed in large part to the extensive competition for the available photosynthetic carbohydrates among multiple sinks such as fruit and shoots (Bepete and Lakso, 1998; Bertin et al., 2002; Lakso et al., 1999). This is further exacerbated by the high demand for carbohydrates from growth-facilitating processes active during this period. In many fruits including apple, early fruit growth is associated with multiple cycles of cell production (Gillaspy et al., 1993; Malladi and Johnson, 2011). Because cell production-related processes are intensive in terms of their requirements for energy and carbohydrates, limitation of carbohydrates during this period may severely impact their 
progression (Bepete and Lakso, 1997; Dash et al., 2012; Lakso et al., 1999). In apple, fruit load reduction during early fruit development resulted in enhanced cell production (Dash and Malladi, 2012; Goffinet et al., 1995). Also, the application of chemical agents that result in fruit removal (thinning) such as benzyl adenine (BA) increased fruit size by increasing the number of cells in the fruit cortex, although some of the response to $\mathrm{BA}$ applications may be attributed to its direct effect on promoting cell production (Wismer et al., 1995). Similarly in tomato, an increase in carbohydrate availability as a result of fruit load reduction at anthesis resulted in higher cell production (Bertin et al., 2002; Fanwoua et al., 2012; Prudent et al., 2010). Together, these studies underline the importance of cell production as a key mechanism mediating the effects of altered carbohydrate availability on early fruit growth.

Nevertheless, several studies have also reported the effects of fruit load manipulation on cell expansion during fruit growth. In apple, fruit load reduction during early fruit development resulted in a minor increase in cell size at maturity (Dash and Malladi, 2012). Application of chemical thinning agents such as naphthaleneacetic acid during early fruit development enhanced final cell size in apple (Wismer et al., 1995). In tomato, although some studies indicated that enhanced fruit growth resulting from fruit load reduction was associated with higher cell expansion (Bertin, 2005; Bertin et al., 2003), others indicated that the effects of fruit load reduction on cell expansion were dependent on the genotype under study (Fanwoua et al., 2012; Prudent et al., 2010).

Several studies have explored the molecular mechanisms associated with the regulation of fleshy fruit growth in response to carbohydrate availability. In tomato, reduction of fruit load before anthesis resulted in changes in the expression of several genes associated with cell proliferation during flower development, including an increase in the expression of cell cycle genes such as B2- and D3-type cyclins and a reduction in the expression of a negative regulator of fruit size, $f w 2.2$ (Baldet et al., 2006). An analysis of changes in the tomato fruit transcriptome during the cell expansion phase (21 d after anthesis), in response to a reduction in fruit load at anthesis, revealed changes in the expression of genes associated with hormone metabolism and signaling, carbohydrate metabolism, and transcriptional mechanisms (Prudent et al., 2010). However, these studies did not investigate the effects of altered carbohydrate availability on molecular mechanisms regulating the progression of the cell production phase of fruit growth, the key phase of fruit development responsive to such manipulation. A recent study that approached this aspect in tomato indicated no significant effects of fruit load reduction on the expression of three cell cycle genes at $7 \mathrm{~d}$ after anthesis (Fanwoua et al., 2012). In apple, the expression of two aintegumenta (ANT) transcription factors associated with cell production, MdANT1 and $M d A N T 2$, was enhanced during early fruit growth in response to a reduction in fruit load (Dash and Malladi, 2012). Beyond these studies, little is known regarding the genes and the mechanisms mediating changes in early fruit growth in response to carbohydrate availability, especially in apple.

The main goal of the current study was to develop an understanding of the molecular mechanisms mediating an increase in apple fruit growth in response to increased carbohydrate availability. A specific objective was to determine if a reduction in fruit load alters carbohydrate concentrations and the expression of genes associated with carbohydrate metabolism. An additional objective was to determine if a reduction in fruit load enhances cell production by altering the expression of key genes associated with the regulation of this process. These objectives were achieved by reducing fruit load during early fruit development and by investigating its effects on carbohydrate metabolism, cell production and expansion, and the expression of key genes associated with these processes.

\section{Materials and Methods}

Plant material. Mature trees (planted in 2001) of 'Golden Delicious' Smoothie (GS) growing on 'M.7a' (M.7a) rootstocks at the Mountain Research and Education Center, University of Georgia, Blairsville, were used in this study. All trees used in these studies were maintained according to commercial apple production practices. The applications of chemical thinning agents were not performed on these trees during the course of this experiment. In 2010, four randomly selected GS trees were subjected to a reduced fruit load (RFL) treatment and four other trees were used as control trees $(n=4)$. Reduction of fruit load involved the removal by hand of all fruit within a cluster except for one lateral fruit at $11 \mathrm{~d}$ after full bloom (DAFB), when fruit were $\approx 5 \mathrm{~mm}$ in diameter. Such a reduction of fruit load at this stage has been previously shown to enhance fruit growth in GS (Dash and Malladi, 2012). In comparison with the control trees, trees under the RFL treatment had 3-fold lower fruit load per trunk cross-sectional area at maturity. Initially, 20 fruit per replicate tree were tagged for fruit diameter measurements. Because many of these fruit dropped during fruit development, fruit diameter was measured on other fruit on these trees. Fruit were randomly sampled (four or more fruit) from these trees at different stages of development and were either fixed in CRAF III fixative $(0.3 \%$ chromic acid, $2 \%$ acetic acid, and 10\% formalin; Berlyn and Miksche, 1976) for cytology or frozen in liquid $\mathrm{N}_{2}$ and stored at $-80{ }^{\circ} \mathrm{C}$ for carbohydrate and gene expression analyses. All sampling was performed around noon. At maturity, 50 fruit per replicate tree were harvested and the average fruit weight (grams) was determined.

Cell number AND Cell area Measurement. The number of cell layers within the fruit cortex and the area of the cortex cells were measured as described previously in Malladi and Johnson (2011). Briefly, cell number was determined by counting the number of cell layers between the petal vascular trace and the epidermis. The relative cell production rate (RCPR) was determined using the cell number data using the formula: $\left[\operatorname{Ln}\left(\mathrm{C}_{2}\right)-\operatorname{Ln}\left(\mathrm{C}_{1}\right)\right] /\left(\mathrm{T}_{2}-\mathrm{T}_{1}\right)$, where $\mathrm{C}_{1}$ and $\mathrm{C}_{2}$ are cell number at time $T_{1}$ and $T_{2}$, respectively. The number of cells within a defined area (grid of known area) was determined at three regions in the fruit cortex between the petal vascular trace and the epidermis, and the average cortex cell area was calculated using these data.

RNA EXTRACTION AND CDNA SYNTHESIS. RNA extraction from flower (0 DAFB) and fruit tissues was performed using the method described in Dash and Malladi (2012). One microgram of total RNA was used for cDNA synthesis after removal of genomic DNA with DNase (Promega Corp., Madison, WI). The synthesis of cDNA was performed in a total volume of $20 \mu \mathrm{L}$, which was subsequently diluted by 6 -fold with autoclaved distilled water and stored at $-20{ }^{\circ} \mathrm{C}$ until further analysis.

Quantitative RT-PCR. Quantitative RT-PCR analyses were performed using the Stratagene Mx3005P real-time 
PCR system (Agilent Technologies, Santa Clara, CA). One microliter of the diluted cDNA was used in a final reaction volume of $12 \mu \mathrm{L}$. The Veriquest SYBR Green qPCR Master Mix $(2 \times)$ was used in this analysis (Affymetrix, Santa Clara, CA). The PCR conditions involved the following cycles: $50{ }^{\circ} \mathrm{C}$ for $2 \mathrm{~min}, 95^{\circ} \mathrm{C}$ for $10 \mathrm{~min}$, and 40 cycles of $95^{\circ} \mathrm{C}$ for $30 \mathrm{~s}$ and $60{ }^{\circ} \mathrm{C}$ for $1 \mathrm{~min}$. Melt curve analyses were performed at the end of these cycles. Controls without a template were used. On rare occasions, some of these negative controls displayed amplification at very late stages of the PCR program. Primer efficiency was determined using LinRegPCR (Ruijter et al., 2009). All gene expression was normalized to the expression of three reference genes, MdACTIN, MdGAPDH (glyceraldehyde 3phosphate dehydrogenase), and MdUBC2 [ubiquitin conjugating enzyme2 (Han et al., 2008)]. Gene expression was calculated from the $\mathrm{Cq}$ values using a method involving correction for amplification efficiency (Pfaffl, 2001). The relative quantities $\left(1 / \mathrm{E}^{\mathrm{Cq}}\right.$, where $\mathrm{E}$ is the efficiency of a given gene and $\mathrm{Cq}$ is the cycle number where the threshold fluorescence level is crossed) was normalized using the geometric mean of the relative quantities of the three reference genes. Expression of a given gene in relation to its expression in the control fruit at 0 DAFB is presented here. Four biological replicates were used in this analysis. The SE of the expression of a gene was determined as described by Rieu and Powers (2009). Statistical analyses were performed on $\log _{2}$ transformed normalized relative quantity values. A list of the genes and primer sequences used in this analysis is presented in Table 1.

Carbohydrate analysis. The carbohydrates, sorbitol, sucrose, fructose, and glucose, were extracted and analyzed as their trimethylsilyl (oxime; TMS) derivatives as described by Tisza et al. (1994). Three of the four replicates from the experiment were used for the carbohydrate analysis. Multiple fruit were pooled within a replicate. Approximately $0.25 \mathrm{~g}$ of the fruit tissue was extracted in $1.5 \mathrm{~mL}$ of $80 \%$ methanol containing phenyl $\beta$-D-glucoside as an internal standard. For derivatization, $100 \mu \mathrm{L}$ of the extract was heated at $40^{\circ} \mathrm{C}$ and the solvent was evaporated to dryness under a stream of nitrogen. Carbohydrates were first converted to their oxime derivatives by adding $25 \mu \mathrm{L}$ hydroxylamine $\left(25 \mathrm{mg} \cdot \mathrm{mL}^{-1}\right.$ in pyridine $)$ and heated to $75^{\circ} \mathrm{C}$ for $30 \mathrm{~min}$. They were subsequently converted to their TMS derivatives by the addition of $70 \mu \mathrm{L}$ of $\mathrm{N}, \mathrm{O}$ bis(trimethylsilyl)trifluoroacetamide $+1 \%$ trimethylchlorosilane. After cooling, the oxime-TMS derivatives of the sugars were analyzed using a gas chromatograph (5890 Series II; Hewlett-Packard, Palo Alto, CA) equipped with a DB5 column (30 $\mathrm{m} ; 0.32 \mathrm{~mm}$ inner diameter). Standards were prepared by dissolving known quantities of sorbitol, sucrose, fructose, glucose, and phenyl $\beta$-D-glucoside in $80 \%$ methanol followed by derivatization as described previously.

Statistical analyses. All statistical analyses were performed using SAS (Version 9.2; SAS Institute, Cary, NC) and Sigmaplot 11 (Systat Software, San Jose, CA). Fruit diameter, cell number, cell area, RCPR, and gene expression data were analyzed using two-way analysis of variance (factors: reduction of fruit load and time after treatment) with repeated measures. Wherever the interactions between the factors were significant, the simple effects were analyzed using test of effect slices $(\alpha=$ $0.05)$. The cell number and cell area data were transformed (square root and $\log$, respectively) before analysis to meet the normality and equal variance assumptions. For carbohydrate accumulation data, Student's $t$ tests were performed on data at
21 DAFB and 28 DAFB. Fruit weight data at maturity were analyzed using the Student's $t$ test.

\section{Results}

REDUCTION IN FRUIT LOAD ENHANCES FRUIT GROWTH. Early fruit growth was enhanced in response to the reduction in fruit load (Fig. 1). Fruit load reduction at 11 DAFB led to significantly larger fruit diameter by 21 DAFB, indicating a rapid response. Fruit size continued to be larger in the RFL treatment during subsequent stages of development. In comparison with the control, fruit in the RFL treatment had $\approx 15 \%$ greater fruit diameter at maturity. The final fruit weight of the control fruit was $168.1 \pm 3.2 \mathrm{~g}$, whereas that of fruit under the RFL treatment was $236.3 \pm 13.4 \mathrm{~g}(P=0.003)$.

REDUCTION OF FRUIT LOAD INCREASES SORBITOL AND FRUCTOSE CONCENTRATIONS AND ALTERS THE EXPRESSION OF GENES ASSOCIATED WITH CARBOHYDRATE METABOLISM. At 21 DAFB, sorbitol and fructose concentrations were higher by 2.2- and 1.6-fold, respectively, in fruit from the RFL treatment, whereas glucose and sucrose concentrations were not significantly altered (Fig. 2). At 28 DAFB, none of the carbohydrates analyzed was significantly different between the control and the RFL treatments. The expression of $M d S D H 1$, one of the genes that encodes for sorbitol dehydrogenase (Nosarzewski and Archbold, 2007), an enzyme involved in the conversion of sorbitol to fructose, was 2.2-fold higher in fruit from the RFL treatment at 18 DAFB but was generally lower than in the control fruit during the rest of fruit development (Fig. 3). In comparison with fruit from the RFL treatment, $M d S D H 2$ expression was higher in the control fruit at 40 DAFB (1.4fold) and at maturity (2.7-fold). The expression of a gene coding for a neutral invertase [MdNINV3 (Li et al., 2012)], involved in the conversion of sucrose to fructose and glucose, did not display an interaction among the factors, reduction of fruit load, and time after treatment. The expression of MdSUSY3, coding for a sucrose synthase involved in the conversion of sucrose to fructose and uridine diphosphate (UDP)-glucose (Li et al., 2012), was higher in fruit from the RFL treatment during early fruit development at 18 $\operatorname{DAFB}(\approx 2$-fold) and 28 DAFB $(\approx 2.7$-fold) but was lower than in the control fruit during the final stages of fruit development.

FRUIT LOAD REDUCTION INCREASES CELL PRODUCTION DURING EARLY FRUIT DEVELOPMENT. Enhanced fruit growth during early development in response to the reduction in fruit load was primarily associated with an increase in cell production in the fruit cortex (Fig. 4). Fruit from the RFL treatment displayed $\approx 6 \%$ higher cell number than the control fruit by $10 \mathrm{~d}$ after treatment (21 DAFB) indicating a rapid increase in cell production as a result of the reduction in fruit load. Toward the end of the cell production phase $(\approx 28$ DAFB $)$, fruit from the RFL treatment had 33\% greater cell number than the control fruit. Fruit from the RFL treatment displayed a higher RCPR between 21 and 28 DAFB by up to 3.5-fold. Cell area within the fruit cortex was slightly greater in the control fruit in comparison with the fruit from the RFL treatment at 40 DAFB $(8 \%)$. However, at maturity, fruit from the RFL treatment displayed $\approx 11 \%$ higher cell area than the control fruit. These data indicate that the reduction in fruit load enhanced early fruit growth primarily by increasing cell production and enhanced cell expansion at late stages of fruit development. 
Table 1. List of genes and the primer sequences used in quantitative RT-PCR analyses of gene expression in response to reduction of fruit load in apple.

\begin{tabular}{|c|c|c|}
\hline Gene & Accession no. ${ }^{\mathrm{z}}$ & Primer sequence $\left(5^{\prime} \text { to } 3^{\prime}\right)^{\mathrm{y}}$ \\
\hline \multirow[t]{2}{*}{$\overline{M d A C T I N}$} & EB127077 & ACCATCTGCAACTCATCCGAACCT \\
\hline & & ACAATGCTAGGGAACACGGCTCTT \\
\hline \multirow[t]{2}{*}{$M d G A P D H$} & EB146750 & TGAGGGCAAGCTGAAGGGTATCTT \\
\hline & & TCAAGTCAACCACACGGGTACTGT \\
\hline \multirow[t]{2}{*}{$M d U B C 2$} & EU586200 & CATTTTGAAAGAGCAGTGGAGCCCT \\
\hline & & TTGCGGTTGTCTCGTACTTTGAACG \\
\hline \multirow[t]{2}{*}{ MdSDH1 } & MDP0000932467 & GAGTCTTGGCGCAGATGCAGT \\
\hline & & ACAGTCGAAGGTTACATCCACTCCATT \\
\hline \multirow[t]{2}{*}{$\mathrm{MdSDH} 2$} & MDP0000874667 & CATTGCCAGCAGTGCAAAGGC \\
\hline & & GGCAATTTAAAGCACAGATCCGCG \\
\hline \multirow[t]{2}{*}{ MdNINV3 } & MDP0000186866 & GTACTCCATGATCCTGTCCGGAATAGT \\
\hline & & CATACCCTTCTGGCATTCAGGCAG \\
\hline \multirow[t]{2}{*}{ MdSUSY3 } & MDP0000126946 & GGAAAAGAATACTGCAGCCGCACG \\
\hline & & GAACTTCGCTGAAAGGTCCGGT \\
\hline \multirow[t]{2}{*}{$M d A N T 1$} & MDP0000175309 & CACCAAGGTGATCGAACCTAACATCCTG \\
\hline & & CCAATGCCGTTGAGAAGGAAGGG \\
\hline \multirow[t]{2}{*}{ MdARF106 } & MDP0000232116 & GAGGGGAAGCCGTTTGAGGT \\
\hline & & GCCGTCCAAAACACCTTCAAT \\
\hline \multirow[t]{2}{*}{$M d C D K B 1 ; 1$} & CV085424 & CGATTGATCTGCGTCGAGCATGTT \\
\hline & & CGGATTCGGCCCCTTCCG \\
\hline \multirow[t]{2}{*}{$M d C D K B 1 ; 2$} & EB138473 & GATTGCTCTGCGTCGAACACGTC \\
\hline & & CCCAGGATTCGGCCCCTTTCT \\
\hline \multirow[t]{2}{*}{$M d C D K B 2 ; 1$} & CV129014 & GGTAACAGAGATGCGCTCTGTAGTAGT \\
\hline & & GAGATTGTTGAGTTGTTGAATCCTATGGA \\
\hline \multirow[t]{2}{*}{$M d C D K B 2 ; 2$} & CV086331 & AGAGAAGCGCTCTGTACTACTGAAGTT \\
\hline & & AAAGCTACTTGCAAATTGTAAACACCAC \\
\hline \multirow{2}{*}{$M d C Y C A 2 ; 1$} & $\mathrm{CO} 416185$ & CAATTGAACACCACCGGTTGTCC \\
\hline & & ACTCGAAGCACCTGAATGGAGG \\
\hline \multirow[t]{2}{*}{$\mathrm{MdCYCA2;2}$} & $\mathrm{CO} 722204$ & CAATTGAACACGACTGGTTGCCT \\
\hline & & CCTCAAACTCAAAGTACCCGAATGCAAA \\
\hline \multirow[t]{2}{*}{$M d C Y C A 2 ; 3$} & $\mathrm{CO} 415585$ & GCAAGAATTACAGTTGAACACTAGTGGTT \\
\hline & & CCGGAAAGTGTACATGTCACAGTCTCT \\
\hline \multirow[t]{2}{*}{$M d C Y C B 1 ; 1$} & CN579062 & AGACACTCAAGCTTCACACTGGTTTC \\
\hline & & AGCAGTGCAACAGCTCCGTG \\
\hline \multirow[t]{2}{*}{$M d C Y C B 1 ; 2$} & CV084069 & GTTCTGGTAACCCTTCATTCGGCA \\
\hline & & AGAAGAGCAACCGCGCTACG \\
\hline \multirow[t]{2}{*}{$M d C Y C B 2 ; 2$} & CV628904 & GTGAAGGAGGTTGGACCGAATC \\
\hline & & CAGTATACGAGCTCAGTTTCTTAGCTTCC \\
\hline \multirow[t]{2}{*}{$M d K R P 4$} & CV084380 & GCTTGCAGAATTCGGCGATGGAAC \\
\hline & & СТCCTCCTCCGCCTCGGA \\
\hline \multirow[t]{2}{*}{$M d K R P 5$} & CN912198 & CCGTCGTCGTATGACGTGGC \\
\hline & & GCCGTCGTTGGAAGTCCGT \\
\hline$M d C O B 1$ & MDP0000288732 & GCAATCATGGATCCAGGACCCAGA \\
\hline & & GGGTCCATCTCCTTTTGTCCGAC \\
\hline$M d C O B L 4$ & MDP0000895592 & CCCTGGCTGGACTCTCGG \\
\hline & & ACGCCACCTTTGCAGCAATTAGAA \\
\hline$M d E X P A 8 ; 1$ & MDP0000138500 & CTTCAACCTACATCTGCATGGTGTG \\
\hline & & TCAAAGCTGCAGTGTTGGTTCCATAT \\
\hline MdEXPA8;2 & MDP0000431696 & GGGTCTTGCTATGAGATGAAATGTGG \\
\hline & & CACCATTGTCGTTGGCCTGC \\
\hline MdEXPA10;1 & MDP0000681724 & GGGTGCGGATCTTGCTACG \\
\hline & & GGAGGGCGTTGTTTGGTGGA \\
\hline
\end{tabular}

${ }^{\mathrm{z}}$ Genbank accession numbers or accession numbers from the Apple Genome Database (Mach, 2007) are presented.

${ }^{\mathrm{y}}$ The forward (top) and reverse (bottom) primers are presented.

EXPRESSION OF MdANT1, A TRANSCRIPTION FACTOR ASSOCIATED WITH THE REGULATION OF FRUIT GROWTH, IS ALTERED IN RESPONSE TO THE REDUCTION IN FRUIT LOAD. Effects of the reduction in fruit load on the expression of MdANT1, an AP2-domain transcription factor, and an auxin response factor (MdARF106) associated with the regulation of fruit growth 


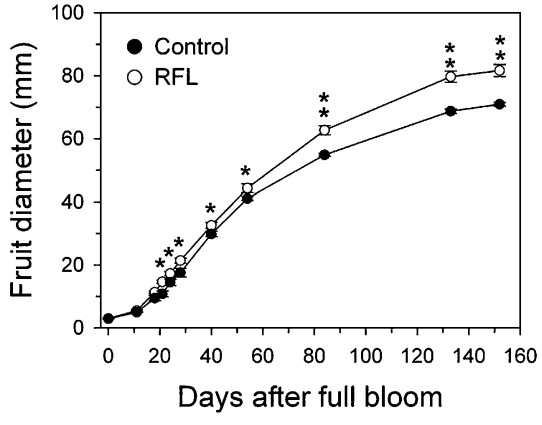

Fig. 1. Effect of reduction of fruit load on fruit growth in apple. Fruit load reduction was performed at $11 \mathrm{~d}$ after full bloom. Fruit diameter was measured from bloom until fruit maturity. Error bars indicate SE $(n=4)$. Asterisks indicate a significant difference between the control and the reduced fruit load (RFL) treatments (single asterisk: $P \leq 0.05$; double asterisk: $P \leq 0.005$; test of effect slices).

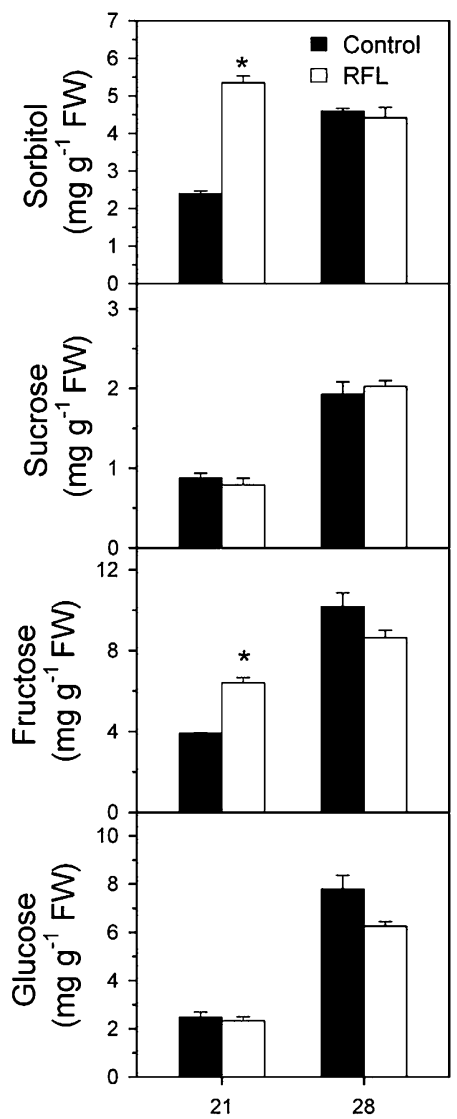

Days after full bloom

Fig. 2. Effect of reduction of fruit load on carbohydrate concentrations in the apple fruit. Reduction of fruit load was performed at $11 \mathrm{~d}$ after full bloom. The concentration of carbohydrates was measured in fruit from the control and the reduced fruit load (RFL) treatments at 21 and $28 \mathrm{~d}$ after full bloom. Asterisk indicates a significant difference between the control and the RFL treatments $(P<0.05)$. Error bars indicate SE $(\mathrm{n}=3)$.

were investigated (Fig. 5; Dash and Malladi, 2012; Devoghalaere et al., 2012). In comparison with the control fruit, MdANTI expression was 2.9- and 5.4-fold higher in fruit from the RFL treatment at 21 and $24 \mathrm{DAFB}$, respectively, the period when differences in cell production and fruit growth were apparent.

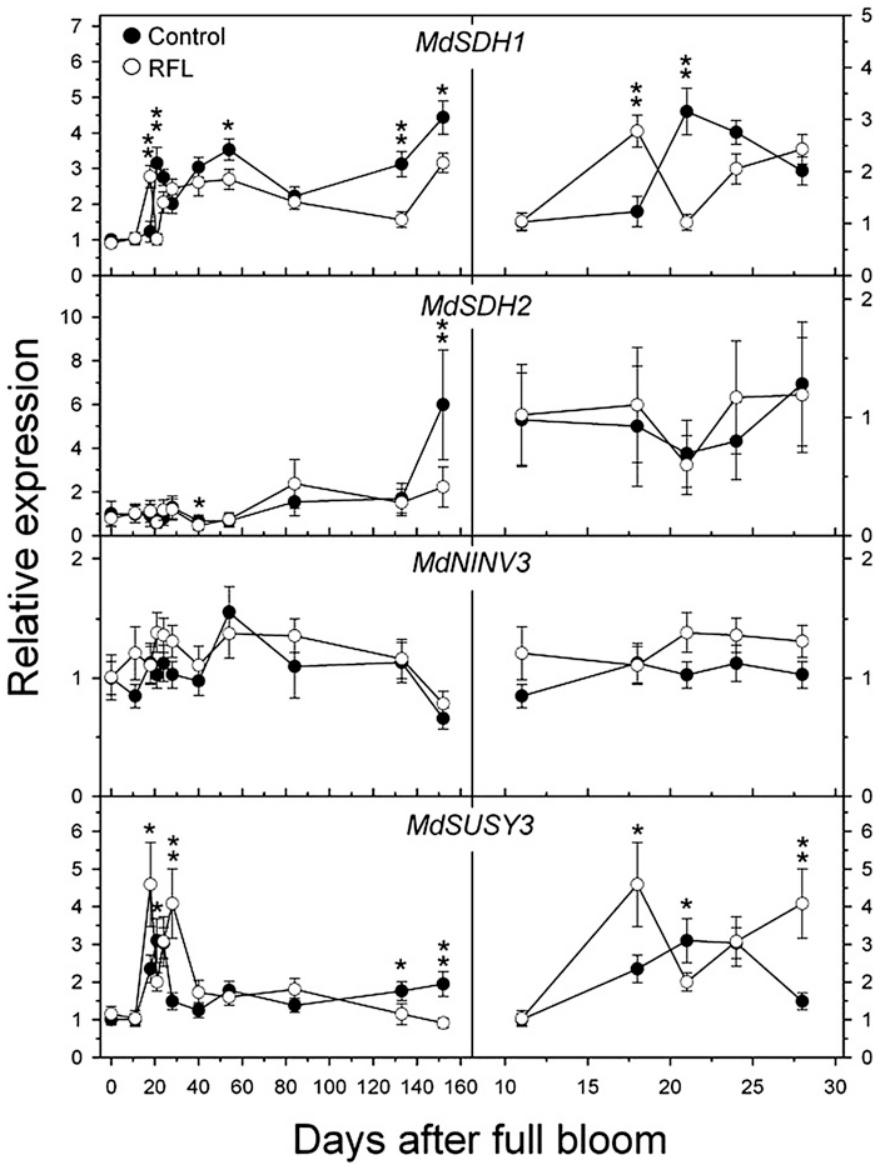

Fig. 3. Effect of reduction of fruit load on the expression of genes associated with carbohydrate metabolism in apple. Fruit load reduction was performed at $11 \mathrm{~d}$ after full bloom (DAFB). All expression data were normalized to the expression of three reference genes. Expression of a gene relative to its expression at 0 DAFB in the control fruit is presented. For each gene, the left panel displays expression during entire fruit development, whereas the right panel displays an expanded version of the data during early fruit growth. Error bars indicate SE $(n=4)$. Asterisks indicate a significant difference between the control and the reduced fruit load (RFL) treatments (single asterisk: $P \leq 0.05$; double asterisk: $P \leq 0.005$; test of effect slices). The factors, reduction in fruit load and time after treatment, did not display a significant interaction in case of MdNINV3.

MdANT1 expression was also higher in fruit from the RFL treatment at 133 DAFB, a period when its general expression was much lower than during early fruit development. MdARF106 expression did not display a significant interaction between the factors, reduction of fruit load and time after treatment.

Altered eXPRession of CELl PROdUCtion AND EXPANSIONRELATED GENES IN RESPONSE TO THE REDUCTION IN FRUIT LOAD. The expression of multiple cell cycle genes, which are positive regulators of cell production (Malladi and Johnson, 2011), increased in response to the RFL treatment during early stages of fruit growth, coincident with the period of increased cell production (Fig. 6). Three of the four B-type cyclin-dependent kinase $(C D K)$ genes $(M d C D K B 1 ; 1, M d C D K B 1 ; 2$, and $M d C D K B 2 ; 2)$ displayed between 1.6- and 5-fold higher expression in fruit from the RFL treatment at 28 DAFB. The expression of two A2-type cyclins, MdCYCA2;1 and $M d C Y C A 2 ; 3$, was also enhanced in response to a reduction in fruit load by up to 4.4- and 4-fold, respectively, during early 


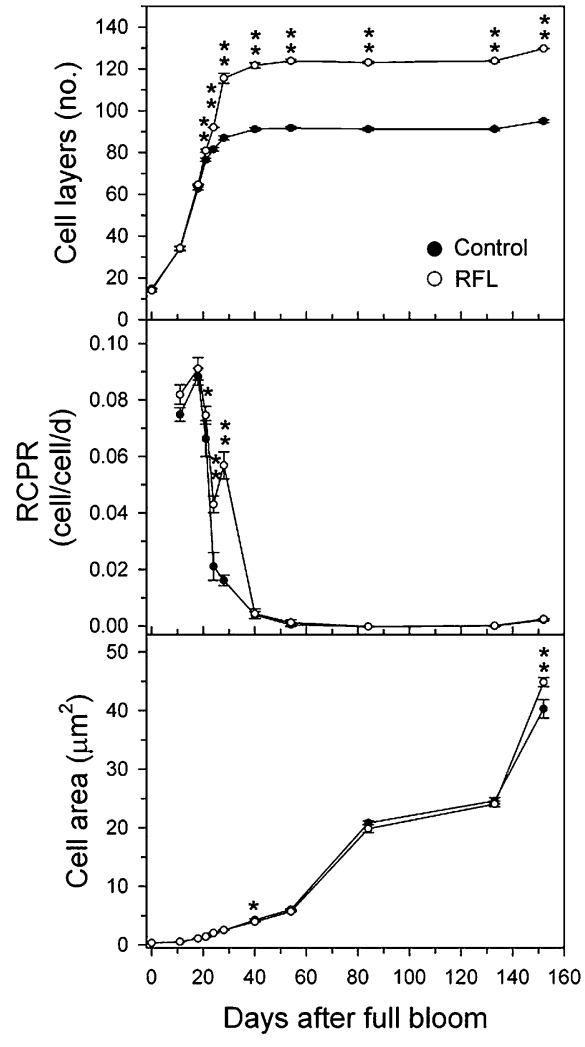

Fig. 4. Effects of fruit load reduction on cell production and expansion in the apple fruit. Fruit load reduction was performed at $11 \mathrm{~d}$ after full bloom. Number of cell layers in the fruit cortex, the relative cell production rate (RCPR), and the cortex cell area were determined in fruit from the control and the reduced fruit load (RFL) treatments. Error bars indicate SE $(n=4)$. Asterisks indicate a significant difference between the control and the RFL treatments (single asterisk: $P \leq 0.05$; double asterisk: $P \leq 0.005$; test of effect slices).

fruit growth (21 to 28 DAFB). The expression of a B1-type cyclin, $M d C Y C B 1 ; 1$, was higher at 28 DAFB by 1.7 -fold, whereas that of a B2-type cyclin, $M d C Y C B 2 ; 2$, was $\approx 2$ - and 3fold higher in fruit from the RFL treatment at 28 and 54 DAFB, respectively. Many of these genes also displayed higher expression in fruit from the RFL treatment at 133 DAFB, a period when their expression was generally much lower than during early fruit development. The expression of MdKRP4 (kip-related protein 4 ), a negative regulator of cell production, was $\approx 3$-fold higher in fruit from the RFL treatment at 133 DAFB. The expression of MdKRP 5 was reduced by 1.6 -fold at 24 DAFB in response to the RFL treatment but was enhanced at 18 (1.8-fold) and 28 DAFB (2.1-fold).

The effect of reduced fruit load on the expression of several genes potentially associated with cell expansion was investigated. The cobra $(C O B)$ and cobra-like $(C O B L)$ genes encode glycosylphosphatidylinositol (GPI)-anchored proteins. $C O B$ genes are associated with cellulose synthesis and directional cell expansion (Roudier et al., 2005; Schindelman et al., 2001), and $C O B L$ genes are associated with cellulose deposition during secondary wall synthesis (Brown et al., 2005; Ching et al., 2006; Li et al., 2003). In tomato, two putative cobra-like genes are present within a quantitative trait locus ( $f w 3.2)$ associated with the control of fruit weight (Zhang et al., 2012). The $\alpha$-type expansin genes encode for proteins putatively

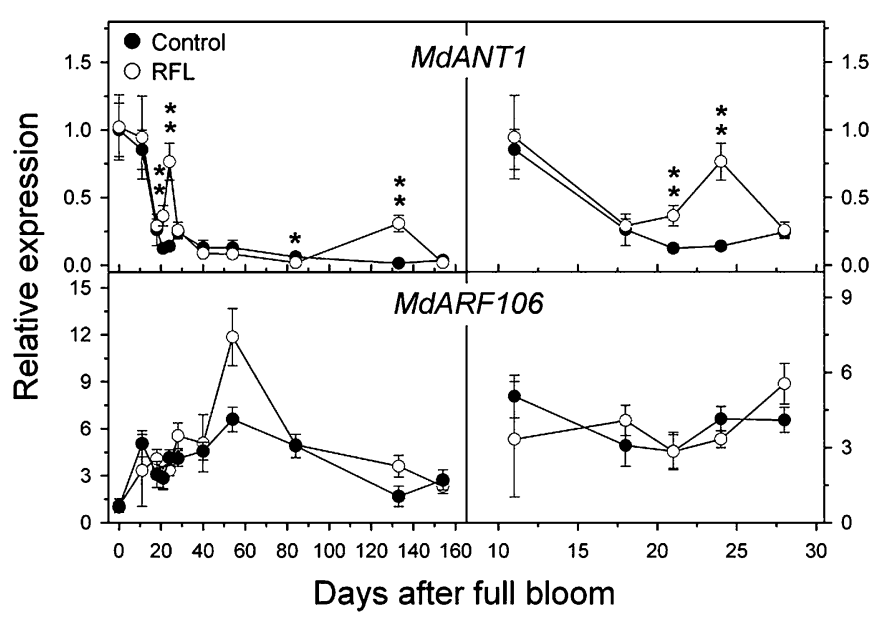

Fig. 5. Effect of a reduction of fruit load on the expression of key transcription factors associated with apple fruit growth. Reduction of fruit load was performed at $11 \mathrm{~d}$ after full bloom (DAFB). The expression data were normalized to the expression of three reference genes. The expression of a gene in relation to its expression in the control fruit at 0 DAFB is presented. For each gene, the left panel displays expression during entire fruit development and the right panel displays an expanded version of the expression data during early fruit development. Error bars indicate SE $(n=4)$. Asterisks indicate a significant difference between the control and reduced fruit load (RFL) treatments (single asterisk: $P \leq 0.05$; double asterisk: $P \leq 0.005$; test of effect slices). The factors, reduction of fruit load and time after treatment, did not display a significant interaction for MdARF106.

associated with cell wall loosening (Cho and Cosgrove, 2000; Sampedro and Cosgrove, 2005). Reduction in fruit load decreased $M d C O B 1$ expression by $1.7-$ to 2.3 -fold at 24 and 28 DAFB (Fig. 7). In contrast, the expression of MdCOBL4 was up to 2.5 -fold higher in fruit from the RFL treatment during early fruit development (24 and 28 DAFB). The expression of MdEXPA8; 1 was enhanced by the RFL treatment at 18 DAFB (2.4-fold) but was subsequently reduced by up to 2.7 -fold (21, 24 , and 28 DAFB). MdEXPA8; 2 expression was higher in fruit from the RFL treatment by up to 2.2-fold during midfruit development (28 and 40 DAFB). MdEXPA8;1 and MdEXPA8;2 also displayed lower expression before maturity and higher expression at maturity in fruit from the RFL treatment. Expression of MdEXPA10;1 was higher in fruit from the RFL treatment during most of fruit development by up to 4.9 -fold.

\section{Discussion}

Reduction of fruit load performed at 11 DAFB, during a period of initiation of intensive growth (Dash and Malladi, 2012; Malladi and Hirst, 2010; Malladi and Johnson, 2011), resulted in a rapid increase in fruit growth by $10 \mathrm{~d}$ after treatment and led to an increase in final fruit size. These data are consistent with previous studies in apple and other fruits in which fruit load reduction enhanced fruit growth and final fruit size (Bertin, 2005; Dash and Malladi, 2012; Goffinet et al., 1995; Morandi et al., 2008; Prudent et al., 2010). An increase in fruit growth in response to a reduction of fruit load has been shown previously to be associated with an increase in cell production in apple and other fruits (Dash and Malladi, 2012; Denne, 1960; Goffinet et al., 1995; Prudent et al., 2010). In the current study, increase in cell number within the fruit cortex was observed within $10 \mathrm{~d}$ (21 DAFB) after the reduction in fruit 


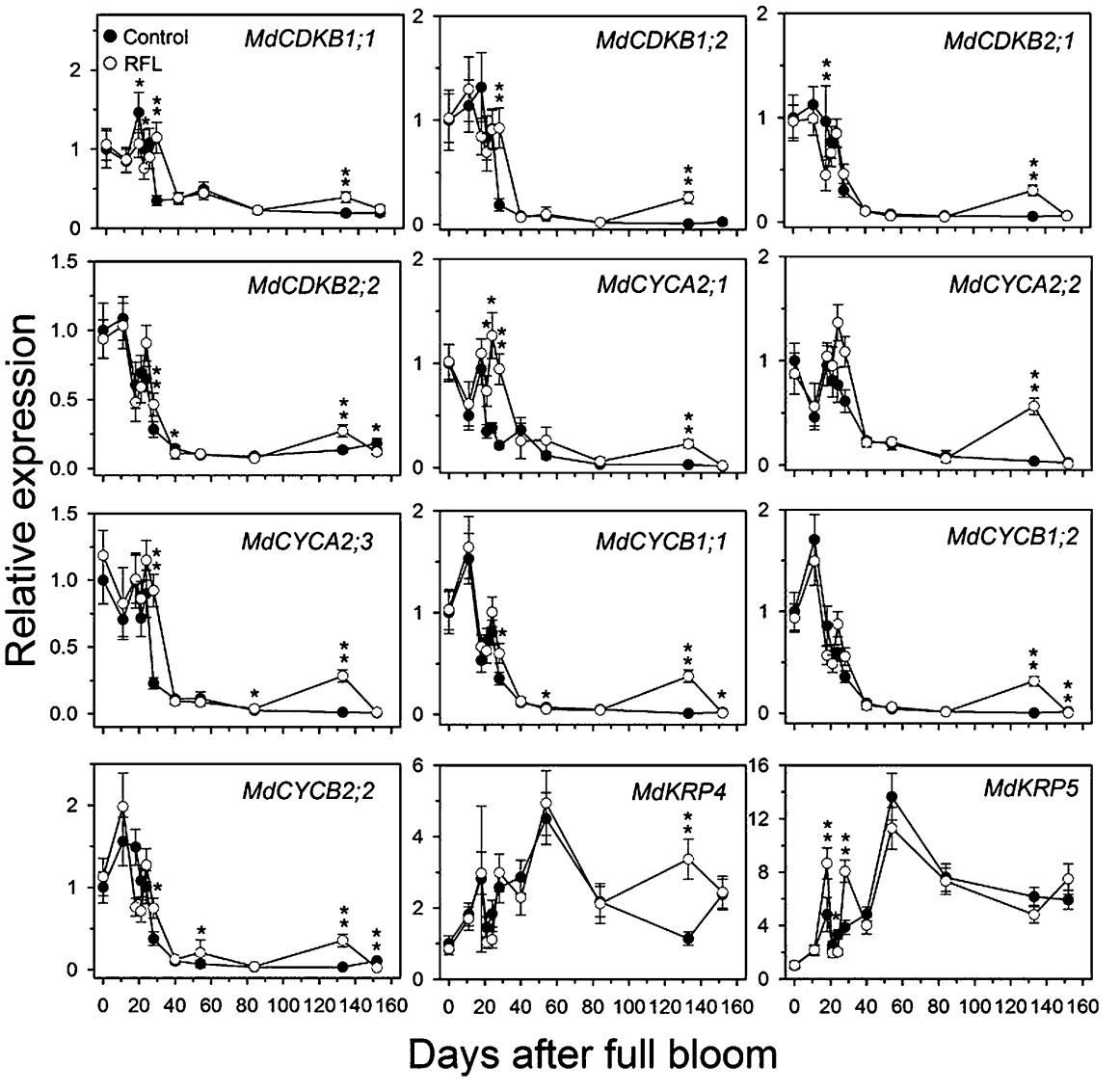

Fig. 6. Effect of a reduction in the fruit load on the expression of core cell cycle genes associated with cell production in the apple fruit. Fruit load reduction was performed at $11 \mathrm{~d}$ after full bloom (DAFB). All expression data were normalized to the expression of three reference genes. Expression of a gene relative to its expression in control fruit at 0 DAFB is presented. Error bars indicate SE $(\mathrm{n}=4)$. Asterisks indicate a significant difference between the control and the reduced fruit load (RFL) treatments (single asterisk: $P \leq 0.05$; double asterisk: $P \leq$ 0.005 ; test of effect slices). $M d C D K B 1 ; 2$ expression was not detectable in the RFL treatment at 154 DAFB. trigger an increase in sorbitol dehydrogenase levels to facilitate its conversion to fructose (Archbold, 1999). This is supported by the increase in fructose concentration in response to the reduction in fruit load at 21 DAFB by 1.6 -fold. In fact, substantial sorbitol dehydrogenase activity has been previously reported during early fruit development in apple (Nosarzewski et al., 2004). MdSDH1 expression was higher in the control fruit at later stages. This may reflect a requirement for higher metabolism of the available sorbitol in the control fruit to meet the requirements for growth. The higher concentration of fructose observed at 21 DAFB may also be a result of enhanced sucrose metabolism. Sucrose imported into the fruit may be converted to fructose and glucose by invertases or to fructose and UDP-glucose by sucrose synthase (Li et al., 2012). The expression of MdSUSY3, one of three potentially important $S U S Y$ genes associated with sucrose metabolism in the apple fruit ( $\mathrm{Li}$ et al., 2012), was generally higher in the RFL treatment during early fruit development. If the reduction in fruit load also increased sucrose influx (in addition to sorbitol) into the fruit, it may be rapidly converted by sucrose synthase, thereby contributing to an increase in fructose

load and was associated with higher RCPR until $\approx 28$ DAFB, indicating greater cell production during early fruit growth. This was the primary mechanism that contributed to the increase in early fruit growth. An increase in cell production may either be a result of a higher rate of cell division within proliferating cells or an increase in the proportion of proliferating cells in the fruit cortex. The former suggests that carbohydrate limitation during early fruit growth affects the rate of progression of proliferating cells through the mitotic cell cycle, while the latter suggests that it affects the timing of exit of the proliferating cells from the mitotic cell cycle. Further work is required to distinguish between these possibilities.

Reduction of fruit load affects the metabolite composition of fruits and these effects are dependent on the stage of fruit development (Do et al., 2010; Morandi et al., 2008; Prudent et al., 2010). In the current study, enhancement of fruit growth in response to the reduction in fruit load was associated with a transient increase in the concentrations of two key carbohydrates during early fruit growth. Sorbitol concentrations in the fruit were rapidly increased in response to the RFL treatment by over 2 -fold by $10 \mathrm{~d}$ after treatment, suggesting that a reduction in fruit load resulted in greater partitioning of the available carbohydrates to the remaining fruit. A transient increase in $M d S D H 1$ expression was observed at 18 DAFB. If an increase in sorbitol influx was already initiated by $18 \mathrm{DAFB}$, it may concentration. At a relatively later stage of fruit development (28 DAFB), no difference in sorbitol and fructose concentrations was observed, indicating that the increase in carbohydrate concentrations was transient and that they were rapidly metabolized to meet the demands of increased fruit growth. Similarly in tomato, carbohydrate concentrations in response to a reduction of fruit load varied during different stages of fruit development (Baldet et al., 2006; Fanwoua et al., 2012; Prudent et al., 2010).

Carbohydrate availability affects cell proliferation (Baldet et al., 2002, 2006; Joubes et al., 2000; Kwon and Wang, 2011; Riou-Khamlichi et al., 2000). In this study, the rapid increase in carbohydrate concentrations and their subsequent metabolism during early fruit development may promote cell production and thereby increase fruit growth. Carbohydrates may facilitate this process by providing the required energy through respiration to support the intensive demands of cell production. Also, carbohydrates may act more directly as signals that regulate the expression of genes, thereby promoting cell proliferation during early fruit growth. For example, sucrose regulates the expression of several cell cycle genes (Baldet et al., 2002, 2006; Joubes et al., 2000; Kwon and Wang, 2011; Riou-Khamlichi et al., 2000).

The expression of multiple genes associated with cell proliferation was affected by the reduction in fruit load. The AP2domain transcription factor, MdANT1, may modulate fruit 


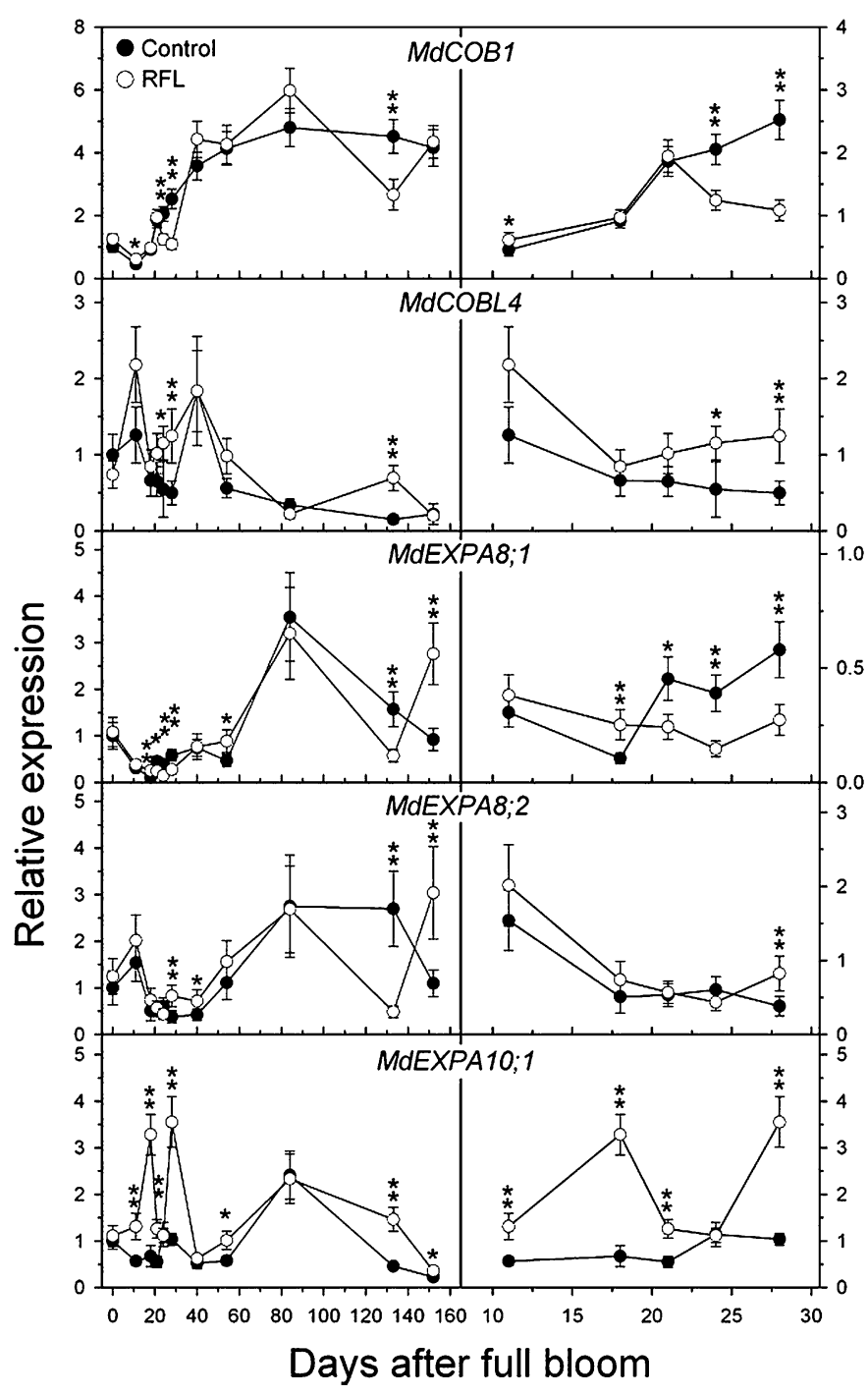

Fig. 7. Effect of a reduction in the fruit load on the expression of genes associated with cell expansion in the apple fruit. Reduction of fruit load was performed at $11 \mathrm{~d}$ after full bloom (DAFB). The expression data were normalized to the expression of three reference genes. Expression of a gene relative to its expression at 0 DAFB in the control fruit is presented. For each gene, the left panel displays data during entire fruit development, whereas the right panel displays an expanded version of the data during early fruit development. Error bars indicate SE $(n=4)$. Asterisks indicate a significant difference between the control and reduced fruit load (RFL) treatments (single asterisk: $P \leq 0.05$; double asterisk: $P \leq 0.005$; test of effect slices).

growth by regulating cell production during apple fruit development (Dash and Malladi, 2012). Expression of MdANT1 was enhanced by up to 5-fold in response to increased carbohydrate availability during early fruit development (21 to $24 \mathrm{DAFB})$. These data are consistent with a previous study in which MdANT1 expression was found to be higher under reduced fruit load conditions (Dash and Malladi, 2012). Also, the expression of $M d A N T 1$ was reduced in response to shading (M. Dash, L.K. Johnson, and A. Malladi, unpublished results), a treatment that reduces carbohydrate availability and fruit growth in apple (Dash et al., 2012). These data suggest that the availability of carbohydrates during early fruit development regulates $M d A N T 1$ expression as a rapid and primary response. MdANT1 may subsequently modulate the expression of downstream target genes associated with cell production, thereby leading to an increase in fruit growth. Cell cycle genes may potentially constitute such target genes of MdANT1. In fact, ANT and ANT-LIKE proteins are known to affect the expression of D3type cyclins (Karlberg et al., 2011; Mizukami and Fischer, 2000).

Increase in carbohydrate availability during early fruit growth was associated with coordinated changes in the expression of cell cycle genes. The expression of seven genes, $M d C D K B 1 ; 1, M d C D K B 1 ; 2, M d C D K B 1 ; 2, M d C Y C A 2 ; 1$, $M d C Y C A 2 ; 3, M d C Y C B 1 ; 1$, and $M d C Y C B 2 ; 2$, was enhanced by the reduction in fruit load by 1.6 - to 5 -fold during the period of increased cell production. A2-type cyclins facilitate the progression of the cell through the $\mathrm{G} 2 / \mathrm{M}$ phase of the cell cycle through their interaction with CDKBs (Boudolf et al., 2009). Similarly, B-type cyclins regulate the progression of the cell through the G2/M phase of the cell cycle (Inze and De Veylder, 2006). These genes have been previously shown to be positively associated with cell production during apple fruit growth (Malladi and Johnson, 2011). These data suggest that coordinated increase in the expression of these cell cycle genes, in response to the reduction in fruit load, facilitates an increase in cell production. Similarly, a decrease in cell production and fruit growth in response to shading in apple fruit was associated with the altered expression of several cell cycle genes, including two A2-type cyclins (Dash et al., 2012). Together, these studies suggest that carbohydrate availability affects cell production during early apple fruit growth by altering the expression of key cell cycle genes associated with the progression of cell proliferation. In tomato, reduction of fruit load before anthesis was associated with an increase in the expression of several cell cycle genes including a B-type CDK and a B2-type cyclin during flower development (Baldet et al., 2006). Also, carbohydrate limitation imposed through prolonged exposure to darkness decreased the expression of several cell cycle genes in tomato fruit, especially during early fruit development (Baldet et al., 2002). Hence, data from the current study, along with previous studies in other fruits, suggest that carbohydrate availability during early fruit growth affects cell proliferation by regulating the expression of genes associated with this process, thereby modulating fruit growth.

Although cell expansion was largely unaffected by the reduction in fruit load, fruit from the RFL treatment displayed slightly larger cell size at maturity. These data are consistent with a previous study with the same genotype, in which a similar increase in cell size was observed during late stages of development under reduced fruit load conditions (Dash and Malladi, 2012), but not with a study on a different apple genotype, 'Empire' (Goffinet et al., 1995). The effect of fruit load reduction on cell expansion and final cell size has been suggested to be genotype-dependent in tomato because it enhanced final cell size in the genotype 'Moneyberg' but not in C9d (Prudent et al., 2010). Similarly in apple, the effects of fruit load reduction on cell expansion may be genotypedependent. Alteration of carbohydrate availability during early fruit growth can influence metabolite accumulation at subsequent stages of fruit development (Do et al., 2010). Such changes in metabolite accumulation at later stages of apple fruit development may allow for greater cell expansion.

Expression of several genes associated with cell expansion was altered by a reduction in fruit load and increased carbohydrate availability, although such changes were not consistently 
associated with differences in cell expansion during fruit growth. $M d C O B 1$ expression was reduced in fruit from the RFL treatment during the period when cell production was enhanced. Similarly, MdEXPA8; 1 displayed higher expression in the control fruit during early fruit growth (21 to 24 DAFB). It may be likely that the developmental increase in the expression of $M d C O B 1$ and $M d E X P A 8 ; 1$ facilitates post-mitotic cell expansion, thereby contributing to fruit growth. Higher expression of these genes may be reflective of the onset and progression of post-mitotic cell expansion in the control fruit during a period when fruit from the RFL treatment display higher cell production. In fact, control fruit had slightly larger cell size at 40 DAFB, after the period when these genes displayed higher expression in these fruit. Conversely, the expression of $M d C O B L 4, M d E X P A 8 ; 2$, and $M d E X P A 10 ; 1$ was enhanced during early fruit growth in response to increased carbohydrate availability. It may be likely that these genes facilitate cell wall synthesis and maintenance associated with increased cell production during this period, roles that require further investigation. The increase in cell size at final stages of development in fruit from the RFL treatment was associated with enhanced expression of the three expansins studied here, suggesting their involvement in facilitating this increase in response to potential changes in metabolite composition during fruit development.

A model is proposed to explain changes in apple fruit growth in response to carbohydrate availability during early development. Availability of carbohydrates such as sorbitol and fructose may directly (as signals) or indirectly (through their metabolism) regulate the expression of key transcription factors associated with fruit growth such as $M d A N T 1$. Such transcription factors may subsequently alter the expression of facilitators of cell production such as the core cell cycle genes, thereby altering the competence for cell production and modulating early fruit growth. Furthermore, changes in the availability of carbohydrates during early fruit growth may alter the fruit metabolome at subsequent stages of development and thereby regulate cell expansion during the final stages of development. Transcriptome and metabolite analyses in response to altered carbohydrate availability during fruit development, particularly during the period of active cell production, may provide further insights into the molecular networks that facilitate fleshy fruit growth.

\section{Literature Cited}

Archbold, D.D. 1999. Carbohydrate availability modifies sorbitol dehydrogenase activity of apple fruit. Physiol. Plant. 105:391-395.

Baldet, P., C. Devaux, C. Chevalier, R. Brouquisse, D. Just, and P. Raymond. 2002. Contrasted response to carbohydrate limitation in tomato fruit at two stages of development. Plant Cell Environ. 25:1639-1649.

Baldet, P., M. Hernould, F. Laporte, F. Mounet, D. Just, A. Mouras, C. Chevalier, and C. Rothan. 2006. The expression of cell proliferationrelated genes in early developing flower is affected by fruit load reduction in tomato plants. J. Expt. Bot. 57:961-970.

Bepete, M. and A.N. Lakso. 1997. Apple fruit respiration in the field: Relationships to fruit growth rate, temperature and light exposure. Acta Hort. 451:319-326.

Bepete, M. and A.N. Lakso. 1998. Differential effects of shade on early-season fruit and shoot growth rates in 'Empire' apple. HortScience 33:823-825.

Berlyn, G.P. and J.P. Miksche. 1976. Botanical microtechnique and cytochemistry. Iowa State University Press, Ames, IA.
Bertin, N. 2005. Analysis of the tomato fruit growth response to temperature and plant fruit load in relation to cell division, cell expansion and DNA endoreduplication. Ann. Bot. (Lond.) 95:439447.

Bertin, N., C. Borel, B. Brunel, C. Cheniclet, and M. Causse. 2003. Do genetic make-up and growth manipulation affect tomato fruit size by cell number, or cell size and DNA endoreduplication? Ann. Bot. (Lond.) 92:415-424.

Bertin, N., H. Gautier, and C. Roche. 2002. Number of cells in tomato fruit depending on fruit position and source-sink balance during plant development. Plant Growth Regulat. 36:105-112.

Bieleski, R.L. 1969. Accumulation and translocation of sorbitol in apple phloem. Aust. J. Biol. Sci. 22:611-620.

Boudolf, V., T. Lammens, J. Boruc, J. Van Leene, H. Van Den Daele, S. Maes, G. Van Isterdael, E. Russinova, E. Kondorosi, E. Witters, G. De Jaeger, D. Inze, and L. De Veylder. 2009. CDKB1;1 forms a functional complex with CYCA2;3 to suppress endocycle onset. Plant Physiol. 150:1482-1493.

Brown, D.M., L.A.H. Zeef, J. Ellis, R. Goodacre, and S.R. Turner. 2005. Identification of novel genes in arabidopsis involved in secondary cell wall formation using expression profiling and reverse genetics. Plant Cell 17:2281-2295.

Ching, A., K.S. Dhugga, L. Appenzeller, R. Meeley, T.M. Bourett, R.J. Howard, and A. Rafalski. 2006. Brittle stalk2 encodes a putative glycosylphosphatidylinositol-anchored protein that affects mechanical strength of maize tissues by altering the composition and structure of secondary cell walls. Planta 224:1174-1184.

Cho, H.T. and D.J. Cosgrove. 2000. Altered expression of expansin modulates leaf growth and pedicel abscission in Arabidopsis thaliana. Proc. Natl. Acad. Sci. USA 97:9783-9788.

Dash, M., L.K. Johnson, and A. Malladi. 2012. Severe shading reduces early fruit growth in apple by decreasing cell production and expansion. J. Amer. Soc. Hort. Sci. 137:275-282.

Dash, M. and A. Malladi. 2012. The AINTEGUMENTA genes, $M d A N T 1$ and MdANT2, are associated with the regulation of cell production during fruit growth in apple (Malus $\times$ domestica Borkh.). BMC Plant Biol. 12:98.

Denne, P. 1960. The growth of apple fruitlet and the effect of early thinning on fruit development. Ann. Bot. (Lond.) 24:397-406.

Devoghalaere, F., T. Doucen, B. Guitton, J. Keeling, W. Payne, T.J. Ling, J.J. Ross, I.C. Hallett, K. Gunaseelan, G.A. Dayatilake, R. Diak, K.C. Breen, D.S. Tustin, E. Costes, D. Chagne, R.J. Schaffer, and K.M. David. 2012. A genomics approach to understanding the role of auxin in apple (Malus $\times$ domestica) fruit size control. BMC Plant Biol. 12:7.

Do, P.T., M. Prudent, R. Sulpice, M. Causse, and A.R. Fernie. 2010. The influence of fruit load on the tomato pericarp metabolome in a Solanum chmielewskii introgression line population. Plant Physiol. 154:1128-1142.

Fanwoua, J., P.H.B. de Visser, E. Heuvelink, G. Angenent, X. Yin, L.F.M. Marcelis, and P.C. Struik. 2012. Histological and molecular investigation of the basis for variation in tomato fruit size in response to fruit load and genotype. Funct. Plant Biol. 39:754-763.

Gillaspy, G., H. Ben-David, and W. Gruissem. 1993. Fruits: A developmental perspective. Plant Cell 5:1439-1451.

Goffinet, M.C., T.L. Robinson, and A.N. Lakso. 1995. A comparison of 'Empire' apple fruit size and anatomy in unthinned and handthinned trees. J. Hort. Sci. 70:375-387.

Han, S.E., Y.S. Seo, S. Heo, D. Kim, S.-K. Sung, and W.T. Kim. 2008. Structure and expression of $M d F B C P 1$, encoding an F-box-containing protein 1, during Fuji apple (Malus domestica Borkh.) fruit ripening. Plant Cell Rpt. 27:1291-1301.

Inze, D. and L. De Veylder. 2006. Cell cycle regulation in plant development. Annu. Rev. Genet. 40:77-105.

Joubes, J., D. Walsh, P. Raymond, and C. Chevalier. 2000. Molecular characterization of the expression of distinct classes of cyclins during the early development of tomato fruit. Planta 211:430-439. 
Karlberg, A., L. Bako, and R.P. Bhalerao. 2011. Short day-mediated cessation of growth requires the downregulation of AINTEGUMENTALIKE1 transcription factor in hybrid aspen. PLoS Genet. 7:e1002361.

Kwon, H.-K. and M.-H. Wang. 2011. The D-type cyclin (Nicta;CycD3;4) controls cell cycle progression in response to sugar availability in tobacco. J. Plant Physiol. 168:133-139.

Lakso, A.N., M. Bepete, M.C. Goffinet, and L.C. Grappadelli. 1998. Aspects of carbon supply and demand in apple fruit. Acta Hort. 466:13-18.

Lakso, A.N., J.N. Wunsche, J.W. Palmer, and L.C. Grappadelli. 1999. Measurement and modeling of carbon balance of the apple tree. HortScience 34:1040-1047.

Li, M., F. Feng, and L. Cheng. 2012. Expression patterns of genes involved in sugar metabolism and accumulation during apple fruit development. PLoS One 7:e33055.

Li, Y.H., O. Qian, Y.H. Zhou, M.X. Yan, L. Sun, M. Zhang, Z.M. Fu, Y.-H. Wang, B. Han, X.M. Pang, M. Chen, and J. Li. 2003. BRITTLE CULM1, which encodes a COBRA-like protein, affects the mechanical properties of rice plants. Plant Cell 15:2020-2031.

Link, H. 2000. Significance of flower and fruit thinning on fruit quality. Plant Growth Regulat. 31:17-26.

Mach, F.E. 2007. Istituto Agrario Di San Michele All'Adige computational biology web resources apple genome. 31 May 2013. <http:// genomics.research.iasma.it/>.

Malladi, A. and P.M. Hirst. 2010. Increase in fruit size of a spontaneous mutant of 'Gala' apple (Malus $\times$ domestica Borkh.) is facilitated by altered cell production and enhanced cell size. J. Expt. Bot. 61:30033013.

Malladi, A. and L.K. Johnson. 2011. Expression profiling of cell cycle genes reveals key facilitators of cell production during carpel development, fruit set, and fruit growth in apple (Malus $\times$ domestica Borkh.). J. Expt. Bot. 62:205-219.

Mizukami, Y. and R.L. Fischer. 2000. Plant organ size control: AINTEGUMENTA regulates growth and cell numbers during organogenesis. Proc. Natl. Acad. Sci. USA 97:942-947.

Morandi, B., L.C. Grappadelli, M. Rieger, and R.L. Bianco. 2008. Carbohydrate availability affects growth and metabolism in peach fruit. Physiol. Plant. 133:229-241.

Nosarzewski, M. and D.D. Archbold. 2007. Tissue-specific expression of SORBITOL DEHYDROGENASE in apple fruit during early development. J. Expt. Bot. 58:1863-1872.
Nosarzewski, M., A.M. Clements, A.B. Downie, and D.D. Archbold. 2004. Sorbitol dehydrogenase expression and activity during apple fruit set and early development. Physiol. Plant. 121:391-398.

Pfaffl, M.W. 2001. A new mathematical model for relative quantification in real-time RT-PCR. Nucleic Acids Res. 29:2002-2007.

Prudent, M., N. Bertin, M. Genard, S. Munos, S. Rolland, V. Garcia, J. Petit, P. Baldet, C. Rothan, and M. Causse. 2010. Genotypedependent response to carbohydrate availability in growing tomato fruit. Plant Cell Environ. 33:1186-1204.

Rieu, I. and S.J. Powers. 2009. Real-time quantitative RT-PCR: Design, calculations, and statistics. Plant Cell 21:1031-1033.

Riou-Khamlichi, C., M. Menges, J.M.S. Healy, and J.A.H. Murray. 2000. Sugar control of the plant cell cycle: Differential regulation of Arabidopsis D-type cyclin gene expression. Mol. Cell. Biol. 20:4513-4521.

Roudier, F., A.G. Fernandez, M. Fujita, R. Himmelspach, G.H.H. Borner, G. Schindelman, S. Song, T.I. Baskin, P. Dupree, G.O. Wasteneys, and P.N. Benfey. 2005. COBRA, an arabidopsis extracellular glycosyl-phosphatidyl inositol-anchored protein, specifically controls highly anisotropic expansion through its involvement in cellulose microfibril orientation. Plant Cell 17:1749-1763.

Ruijter, J.M., C. Ramakers, W.M.H. Hoogaars, Y. Karlen, O. Bakker, M.J.B. van den Hoff, and A.F.M. Moorman. 2009. Amplification efficiency: Linking baseline and bias in the analysis of quantitative PCR data. Nucleic Acids Res. 37:e45.

Sampedro, J. and D.J. Cosgrove. 2005. The expansin superfamily. Genome Biol. 6:242.

Schindelman, G., A. Morikami, J. Jung, T.I. Baskin, N.C. Carpita, P. Derbyshire, M.C. McCann, and P.N. Benfey. 2001. COBRA encodes a putative GPI-anchored protein, which is polarly localized and necessary for oriented cell expansion in Arabidopsis. Genes Dev. 15:1115-1127.

Tisza, S., P. Sass, and I. Molnar-Perl. 1994. Optimization of the simultaneous determination of acids and sugars as their trimethylsilyl (oxime) derivatives by gas chromatography-mass spectrometry and determination of the composition of six apple varieties. J. Chromatography 676:461-468.

Wismer, P.T., J.T.A. Proctor, and D.C. Elfving. 1995. Benzyladenine affects cell division and cell size during apple fruit thinning. J. Amer. Soc. Hort. Sci. 120:802-807.

Zhang, N., M.T. Brewer, and E. van der Knaap. 2012. Fine mapping of $f w 3.2$ controlling fruit weight in tomato. Theor. Appl. Genet. 125:273-284. 